DOSSIÊ

\title{
APONTAMENTOS PARA ANÁLISE DA CORRELAÇÃO DE FORÇAS NA EDUCAÇÃO BRASILEIRA: EM PROL DA FRENTE DEMOCRÁTICA
}

\author{
ROBERTO LEHER ${ }^{1}$ (D)
}

RESUMO: $\mathrm{O}$ artigo analisa os principais grupos sociais que atuam na definição da educação brasileira e faz apontamentos para a análise da correlação de forças entre esses segmentos, destacando as mudanças advindas das eleições presidenciais de 2018. Caracteriza a composição da equipe do Ministério da Educação e da área de ciência e tecnologia e, ao final, propugna a importância da frente em defesa da educação pública, gratuita, laica e comprometida com a formação do espírito científico das novas geraçóes.

Palavras-chave: Educação brasileira. Políticas públicas. Correlação de forças. Forças sociais influentes. Liberdade acadêmica.

\section{NOTES FOR ANALYSIS OF THE CORRELATION OF FORCES IN BRAZILIAN EDUCATION: IN DEFENSE OF THE DEMOCRATIC FRONT}

ABSTRACT: This article analyzes the main social segments that define Brazilian education and makes notes for the analysis of the correlation of forces between these groups, highlighting the changes coming from the presidential elections of 2018. It characterizes the composition of the staff of the Ministry of Education and the area of Science and Technology and, at the end, advocates the importance of the front in defense of public, free, and secular education, committed to the formation of the scientific spirit of new generations.

Keywords: Brazilian education. Public policies. Correlation of forces. Influential social forces. Academic freedom.

\footnotetext{
${ }^{1}$ Universidade Federal do Rio de Janeiro, Faculdade de Educação - Rio de Janeiro (RJ), Brasil.

E-mail: leher.roberto@gmail.com

DOI: 10.1590/ES0101-73302019219831
} 


\title{
APUNTES PARA EL ANÁLISIS DE LA CORRELACIÓN DE FUERZAS EN LA EDUCACIÓN BRASILEÑA: A FAVOR DEL FRENTE DEMOCRÁTICO
}

\begin{abstract}
RESUMEN: El artículo analiza los principales grupos sociales que actúan en la definición de la educación brasileña y hace apuntes para el análisis de la correlación de fuerzas entre esos segmentos, destacando los cambios surgidos de las elecciones presidenciales de 2018. Analiza la composición del equipo del Ministerio de Educación y del área de Ciencia y Tecnología y, al final, propugna la importancia del frente en defensa de la educación pública, gratuita, laica y comprometida con la formación del espíritu científico de las nuevas generaciones.
\end{abstract}

Palabras clave: Educación brasileña. Políticas públicas. Correlación de fuerzas. Fuerzas sociales influyentes. Libertad académica.

\section{Introdução}

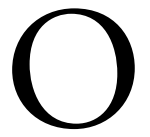

Centro de Estudos Educação e Sociedade (Cedes) está assentado em impactante trajetória histórica. São exemplos o complexo período da chamada transição democrática, a elaboração do capítulo dedicado à educação na constituinte de 1987-1988, a realização das Conferências Nacionais de Educação, os difíceis anos de luta pela elaboração de uma Lei de Diretrizes e Bases (LDB) que cumprisse um papel construtivo na estruturação da escola pública e a reorganização da frente ampla em prol da educação pública nos anos 2000. Em seu VI Seminário da Educação Brasileira, ocorrido na Universidade Estadual de Campinas (Unicamp), em dezembro de 2018, reafirmou sua tradição de contribuição original sobre os rumos da educação pública ao interpelar sobre a nova educação e as orientaçôes hegemônicas em debate.

No processo da campanha eleitoral de 2018, excetuando parcialmente os estados nordestinos, o principal tema educacional foi a promessa de uma escola sem partido, inexistindo proposiçóes muito além dessa pauta. $\mathrm{O}$ fato de essa narrativa ter conquistado grande auditório é, em si, um problema relevante de pesquisa. Ela encontra-se em descompasso com a agenda educacional propagada por setores vinculados ao mercado (e, mais precisamente, ao bloco no poder, utilizando o conceito de Poulantzas, 1981) e, com muito mais profundidade, em confronto com a agenda dos movimentos em defesa da educação pública. O Seminário Cedes reporta-se à disputa de hegemonia a que se refere Gramsci (2012) no Caderno 13 ao mencionar, explicitamente, "orientaçōes hegemônicas".

O presente artigo tem o desafio de contribuir para deslindar esse complexo problema - uma exigência para os debates e as avaliaçóes sobre o curso dos 
acontecimentos. A análise segue a perspectiva apontada por Gramsci (2012) de que a investigação da correlação de forças é condição obrigatória para informar estrategicamente os sujeitos coletivos envolvidos em lutas sociais, como na construção da escola pública de que o Brasil necessita.

\section{Estado e correlação de forças}

Poulantzas (1981) define o Estado capitalista como condensação material de uma relação de forças. Considerar, a priori, o chefe de governo e seus ministros como os detentores do verdadeiro poder do Estado denota incompreensáo sobre o Estado capitalista. Sem examinar os nexos Estado e sociedade civil, pouco pode ser dito sobre o poder dos governantes. Aqui se trata de incorporar na investigaçáo os setores dominantes que constituem o bloco no poder. Existem contradiçôes, fissuras, tensōes no aparato de Estado e isso alcança, também, as políticas e as orientaçōes educacionais do Estado, mas, no âmbito estatal essas contradiçóes e fissuras não são indiferenciadas, um caldeirão de expectativas distintas entre grupos dominantes e subalternos (aqui incluindo os sindicatos dos trabalhadores). O vigor da força analítica de Poulantzas (1981) deve-se à importantíssima diferenciação entre o que o autor denomina de "bloco no poder", classes-apoio e classes dominadas.

Por bloco no poder, entendo as classes e fracçóes de classe que ocupam o espaço da dominação política, quer dizer a ou as classes e fracçóes dominantes. [...] Em contrapartida, aquelas classes, entre as classes dominadas, que têm uma função particular em relaçáo ao bloco no poder, quer dizer as que apoiam muito claramente o poder do bloco de poder, [denomino como] classe-apoios do bloco no poder. [...] [A propósito do bloco no poder] Não me refiro ao conjunto das camadas que apoiam o poder de Estado, refiro as que participam no espaço da dominação política, portanto aquelas que têm áreas de poder próprias no seio do aparelho de Estado (POULANTZAS, 1981, p. 91).

As classes representadas no bloco no poder possuem "sedes, bastióes de poder (os verdadeiros centros de poder) relativamente autônomos no âmbito do Estado" (POULANTZAS, 1981, p. 92). Distintamente, os subalternos e as classes-apoio não se manifestam por células autônomas de poder próprio. As contradiçōes intraburguesas, ainda que externas ao bloco no poder, atravessam o Estado de modo mais direto do que as contradições dominantes e subalternos: estes interpóem resistências e limites, mas não definem o fulcro do Estado, guardando maior distância.

Como coalizão de classe e fraçóes de classes dominantes, o bloco no poder no Brasil é constituído das fraçôes que operam o capital comércio de dinheiro, o agronegócio, o setor de commodities, os serviços em processo monopólico e as 
fraçóes industriais. Todas essas fraçóes possuem zonas de interseção, desautorizando a definição de um conjunto financeiro-especulativo e de outro conjunto produtivo. Isso náo quer dizer que formam um todo indiferenciado, um amálgama das fraçóes de classe. Existe uma clara hierarquia: os operadores do capital comércio de dinheiro estão em posição diferenciada, acima das demais fraçóes. A simples análise da gestão e apropriação do gigantesco fundo público do Estado confirma esse lugar proeminente (FATTORELLI; ÁVILA, 2019).

A despeito das contradições e fissuras, as frações financeiras e industriais hegemonizaram uma transformação profunda no padrão de acumulação do capital no Brasil, com o agravamento da crise econômica de 2013. As suas exigências em relação à apropriação privada do fundo público, aos direitos trabalhistas, à previdência social, à exploração das commodities, ao agronegócio, à remoção de obstáculos e entraves ambientais e à flexibilização da demarcação dos territórios dos povos indígenas definiram nova agenda para o Estado, que somente poderia se viabilizar se assentada em bases autocráticas. Náo é objetivo examinar aqui o modo como o governo Dilma Rousseff tentou se equilibrar diante dessas mudanças (ver LEHER, 2018). O resultado foi conhecido: o impeachment extralegal que destituiu Dilma do governo. Sáo frutos desse processo a Emenda Constitucional no 95/2016, a contrarreforma trabalhista (Lei no 13.467/2017), a flexibilização ambiental e a da legislaçáo de terras. Mas o governo Michel Temer apenas iniciou o processo de recalibração do padrão de acumulação. Objetivando seguir na mesma agenda regressiva, sem alternativas exequíveis e realistas, o bloco no poder convergiu no apoio à candidatura de Jair Bolsonaro.

A correlação de forças na educação tem de considerar esses deslocamentos políticos, em que as classes dominantes se moveram, quase sem dissensôes, para o campo de apoio a um candidato que não guardava afinidade com a agenda neoliberal ortodoxa e, menos ainda, com o pensamento econômico neoclássico e, ao mesmo tempo, em que grupos religiosos pentecostais e neopentecostais igualmente aderiram a esse candidato recém-convertido evangélico.

No processo eleitoral brasileiro de 2018 (governadores, deputados, senadores e presidente da república), os operadores econômicos apoiaram forças políticas e candidaturas que professaram apreço por uma agenda educacional explicitamente diferente da manejada pelos seus próprios centros de pensamento. Tal contradição tem a ver com o fato de que sua pauta econômica e social se tornou incompatível com concessões democráticas. A opção pelo aprofundamento da agenda neoliberal (privatizaçôes, desregulamentação ambiental, flexibilização dos direitos trabalhistas, reforma da previdência etc.) teve como corolário o aprofundamento da autocracia, e essa opção requer jogar às favas os mais rarefeitos escrúpulos democráticos (LEHER, 2018). Nesse sentido, em virtude da profunda crise de suas agremiaçóes partidárias, Democratas (DEM), Partido da Social Democracia Brasileira (PSDB), Movimento Democrático Brasileiro (MDB) optaram por apoiar o impeachment de Rousseff e, depois, quando se tornou evidente 
que suas candidaturas presidenciais naufragaram, unificaram o apoio a Bolsonaro e aos candidatos de perfis semelhantes nos estados.

Metodologicamente, a análise da correlação de forças exige a caracterização dos principais grupos sociais (na acepção de Gramsci, 2012) que ocupam os postos mais importantes do governo federal, assim sintetizados:

- bloco no poder;

- tecnocracia militar;

- judiciário e aparato policial federal;

- $\quad$ ideológicos (concebido como classes-apoio) (POULANTZAS, 1981).

A título de síntese, aborda-se o que poderia ser uma agenda construtiva capaz de proporcionar melhores condiçóes para a educação brasileira.

\section{Bloco no poder}

O núcleo mais forte e de maior aderência ao bloco no poder é liderado pelo ministro da Economia Paulo Guedes, proveniente da Escola de Chicago. Reúne bancos, agronegócio e setor de commodities, setores industriais, redes comerciais de grande porte e empreiteiras. Esse é o estado maior do capital. Como contrapartida ao apoio ao candidato Bolsonaro, logrou total liberdade para realizar as nomeaçóes de seu interesse. Emplacou os presidentes do Banco Central, Banco do Brasil, Caixa Econômica Federal, Banco Nacional de Desenvolvimento Econômico e Social (BNDES), Petrobras, muitos deles também com formação em Chicago, e assegurou o deslocamento do comércio exterior da alçada do Ministério das Relaçóes Exteriores para a nova pasta. Como possuía carta branca para as nomeaçóes, avançou na sugestão de indicação de um quadro do Todos pela Educação (TPE) Mozart Ramos como ministro da Educação e, conforme anunciado pela imprensa, com apoio do presidente, entretanto a bancada evangélica ameaçou uma guerra santa contra o governo, que, desse modo, recuou na indicação (MURAKAWA; DELGADO, 2018). Prevaleceu, nesse caso, a indicação do chamado guru do núcleo familiar de Bolsonaro, Olavo de Carvalho, que sugeriu Ricardo Vélez Rodríguez para o cargo (MURAKAWA, 2018). Suas interfaces com a educação serão examinadas em seção específica, adiante.

\section{Tecnocracia militar}

O segundo nódulo mais relevante é composto de militares de diferentes perfis. Como assinala Florestan Fernandes (1976, p. 103): "É um erro crasso querer 
transformar o militar, individual ou coletivamente, em uma categoria pura e na última ratio dos processos históricos. [...] Não é um agente político que trabalhe para si próprio (como uma categoria social), ou para um setor particular da sociedade (como um estrato burocrático das classes-médias 'tradicionais' ou 'modernas')". A grande participação de quadros provenientes das forças armadas no governo Bolsonaro dá-se em contexto distinto ao do período da ditadura empresarial-militar trata-se de um governo eleito e a participação de seus integrantes não é institucional. Os quadros militares são convocados como medida anticorrupçâo e como sujeitos guiados por uma razão técnica, isto é, não ideológica (nesse sentido, o discurso legitimador é semelhante ao de outrora). Se no período da ditadura empresarial-militar a doutrina de segurança presidiu a coesão ideológica, no atual contexto não há, até a data de conclusão do artigo, em 31 de janeiro de 2019, explicitação de uma doutrina geral que confira unidade ideológica dos quadros no governo ${ }^{1}$.

A particularidade da situação brasileira, em 2019, deve-se ao fato de que os quadros provenientes das forças armadas são numerosos e estão ancorados na presidência e, como assinalado, em ministérios relevantes, contudo essa condição não equivale à de setores sociais com autonomia decorrente de seu poder como classe. A coexistência dos militares com o nódulo do bloco no poder provavelmente será lastreada pelo teor e pelos objetivos da agenda econômica da alta finança. A pauta das chamadas reformas pode gerar tensóes (aposentadoria dos militares), visto que a realidade da Emenda Constitucional no 95/2016 pressupóe escasso espaço para discussóes, controvérsias e tolerância com a divergência.

Ocupam postos-chave no governo Jair Bolsonaro mais de 30 militares (NEVES, 2019). Somente no Planalto são 18 generais, cujos destaques são Augusto Heleno, da Segurança Institucional (e seu substituto, General Valério Stumpf); Carlos Alberto dos Santos Cruz, da Secretaria de Governo; Fernando Azevedo e Silva, ministro da Defesa; Eduardo Villas Bôas, comandante do exército; Tarcísio Gomes de Freitas, Ministério dos Transportes, Portos e Aviação Civil; e Hamilton Mourão (da Academia Militar das Agulhas Negras - Aman), vice-presidente da república. Cabe destacar que muitos desses generais estiveram na missáo da Organização das Nações Unidas (ONU) no Haiti (Augusto Heleno, Carlos Alberto, Tarcísio Gomes). Ademais, vários outros militares ocupam diversas pastas e cargos dos segundo e terceiro escalóes, conforme discutido adiante na análise da composição do Ministério da Educação (MEC).

\section{Amálgama Judiciário, Ministério Público e Executivo}

Composta de amálgama do judiciário e do Ministério Público, liderado por Sérgio Moro como ministro da Justiça e Segurança Pública, esta é uma pasta que possui forte interseçáo com o bloco no poder (como as atribuiçôes do Conselho de Controle de Atividades Financeiras - Coaf) e, também, 
com o núcleo ideológico, a exemplo da questão da flexibilização da posse de armas (UOL, 2019) e do Pacote de Segurança (alternaçóes no Código Penal, na Lei de Execução Penal, no Código Eleitoral, entre outros), que assimila a agenda do núcleo ideológico, como a condenação em segunda instância e a autorização de abate quando "sob escusável medo, surpresa ou violenta emoção" ou "risco iminente de conflito armado" (MENDES, 2019, p. 82), medidas que podem se aproximar de uma pena de morte sem julgamento, a critério do policial.

\section{Núcleo ideológico: correntes religiosas, movimentos de direita e think tanks}

O núcleo ideológico, sob influência de Olavo de Carvalho e das correntes religiosas e operacionalizado pelo núcleo familiar do presidente, está representado no governo pelos ministros da Educação, das Relaçóes Exteriores e da Mulher, da Família e dos Direitos Humanos. Pode ser caracterizado como classes-apoio, pois náo possui nexo orgânico nem poder próprio que o coloque no bloco no poder. Não significa, contudo, que não tenha influência relevante. Jair Bolsonaro venceu a eleição, em grande parte, em virtude do protagonismo desses grupos - pentecostais, neopentecostais, movimentos e iniciativas vinculadas a think tanks da extrema direita. São relevantes as grandes votaçóes de parlamentares vinculados a tais movimentos. As correntes religiosas (bancada evangélica) possuem considerável influência no parlamento, mas não é um grupo homogêneo nem majoritário. Conforme o Departamento Intersindical de Assessoria Parlamentar (Diap), foram eleitos 84 deputados e sete senadores, entre pastores, missionários, sacerdotes, cantores gospel e parlamentares que guiam suas votaçōes por preceitos religiosos (DIAP, 2018) ${ }^{2}$. Em muitas votaçôes, esse setor atua em conjunto com a bancada ruralista e com a composta de policiais linha dura. Na legislatura anterior, o Projeto de Lei (PL) no 7.180/2014, que dispunha sobre a Escola sem Partido, acabou arquivado, com, é bom ressaltar, o apoio da liderança do DEM e do PSDB.

Tal núcleo sustenta uma agenda educacional que é considerada pelo bloco no poder como anacrônica e incapaz de alterar a debilidade da educaçáo pública brasileira (e da força de trabalho), entretanto é uma orientação que não pode ser descartada do cenário político-educacional: as classes dominantes não podem prescindir do apoio dessas forças, tampouco o novo governo. De fato, a sua agenda regressiva exige a manutenção dessas forças como classes-apoio e, por isso, as suas pautas seguirão ativas.

\section{Contradições no campo educacional}

Entre os centros de pensamento educacionais organicamente vinculados ao bloco no poder, é possível listar coalizóes como: TPE; Movimento Brasil 
Competitivo; fundações corporativas, como Fundação Lemann, Unibanco, Itaú e Bradesco; entidades sindicais patronais, como Confederação Nacional da Indústria, Federação das Indústrias do Estado de São Paulo e congêneres, Confederação da Agricultura e Pecuária do Brasil, Associação Brasileira do Agronegócio; diversos think tanks, como Casa das Garças, Millenium, Diálogo Interamericano, assim como meios de comunicação - Grupo Globo (incluindo Valor), Folha de S.Paulo, $O$ Estado de S. Paulo, revista Exame. Ademais, existem grupos de poder vinculados aos próprios negócios educacionais, como Associação Brasileira de Mantenedoras de Ensino Superior, Associação Brasileira para o Desenvolvimento da Educação Superior, Federação Nacional das Escolas Particulares e Associação Nacional das Universidades Particulares (LEHER, 2018).

Os anseios, as expectativas, as açóes educacionais dos setores dominantes estão, grosso modo, estabelecidos pelas entidades listadas. Na educação básica, os interesses gerais do bloco estáo predominantemente sob a direçáo do TPE (que claramente atua como partido, em acepção gramsciana) e pela Fundaçáo Lemann; na formação profissional, das entidades patronais e do Movimento Brasil Competitivo; e no caso da educaçáo superior, as privadas-mercantis, além das entidades corporativas já listadas, possuem apoios no mundo das finanças. As universidades públicas sofrem influências difusas do governo federal, de agências de fomento, de think tanks, de organismos internacionais (Organização para a Cooperação e Desenvolvimento Econômico - OCDE, Banco Mundial, Organização das Nações Unidas para a Educação, a Ciência e a Cultura), empresas que estabelecem rankings, meios de comunicação, entidades patronais, fundações corporativas, grandes empresas, sindicatos, coletivos estudantis, cada um com peso diferenciado conforme a conjuntura.

A influência da agenda educativa do Banco Mundial, da OCDE e de programas educacionais em curso nos Estados Unidos é destacada. Em comum, a definição de uma pedagogia, em sentido durkheimiano, afim à socialização da força de trabalho, baseada nas competências, na definiçấo de metas de aprendizagem consubstanciadas por descritores, na avaliação externa e censitária, na intensificação tecnológica e na correspondente expropriação de conhecimentos dos docentes. São diversas miradas, nuanças e objetivos específicos - da preparação dos trabalhadores para a indústria 4.0, até a constituição de robusto segmento de negócios educacionais, passando pela indústria de cartilhas e livros didáticos, convergentes, em geral, na tecnicização do fazer educacional. A análise das principais leis e normas da educaçẫo básica, profissional e superior, como a Lei no 13.005/2014, corrobora a proposição de que as demandas da sociedade civil (por meio de seus aparelhos privados de hegemonia) se forjam como Estado, pela conversão dessas demandas em lei, nos termos do conceito de Estado integral de Gramsci (2012).

A análise do bloco no poder precisa considerar a ação direta do capital. As organizaçóes empresariais controlam grande parte da educação superior 
mercantil, notadamente pela açáo dos fundos de investimentos, que têm promovido agressiva política de aquisições, conformando forte monopolização do setor. Esse segmento atua, igualmente, nas escolas de educação básica particulares, principalmente para o público de maior renda. Ademais, os fundos têm promovido aquisiçóes dos grupos editoriais e, cada vez mais, estáo propagando cartilhas e manuais diretamente nas escolas, abrangendo dezenas de milhares de unidades. Alcançam, assim, o cháo da escola, influenciando o teor das aulas e o que é dado a pensar pelas crianças e jovens. Como esses grupos possuem capital aberto e têm ações na bolsa de valores, a educação passa a estar inserida na dinâmica de tempo de rotação do capital característico da bolsa de valores. O período de expansão vertiginosa dos fundos de investimentos deve-se a políticas públicas, como o Fundo de Financiamento Estudantil (Fies) e o Programa Universidade para Todos (ProUni). Sem o crescente repasse de verbas públicas (2010-2015) para as empresas, náo teria ocorrido a expansão do mercado educacional do ensino superior.

É possível aduzir, e estudos sobre o tema devem ser estimulados, que a ascendência dessas organizaçóes sobre o conjunto da educação brasileira é muito maior do que a fatia do mercado por elas ocupada. De fato, as interfaces dessas corporaçóes com a educação básica compreendem o fornecimento de material didático, a difusão dos chamados sistemas de ensino e, muito importante, a massiva formaçáo de professores, de maneira especial a distância.

Embora exista considerável diversidade de perspectivas educacionais no bloco no poder, é possível delinear suas linhas de força. A base filosófica comum, ainda que tácita, é utilitarista (LAVAL, 2003). A conexão entre a educação e a economia ocorre por meio da teoria do capital humano. Essas linhagens filosóficas estáo contidas na agenda do TPE, conjugadas com princípios liberal-democráticos, como a laicidade, a defesa da gratuidade, o caráter universal da educação básica, o respeito à diversidade racial, às orientaçôes sexuais e o reconhecimento de certos traços de cidadania. A gestão escolar é referenciada no management (metas, remuneraçáo por resultados, rankings).

A influência do capital na educação, relexicalizada como participação da sociedade civil, é reivindicada como dimensão dinamizadora e capaz de conferir maior objetividade ao ensino, conferindo às medidas educacionais realismo político: uma pedagogia direcionada para reduzir conflitos, por meio da combinaçáo do capital social com a difusão de certo ethos do capital emocional que propicie resiliência nas relaçôes de trabalho adversas. Os docentes são concebidos como profissionais que desempenham tarefas pedagógicas, e não como intelectuais inventivos.

É perceptível uma contradição estrutural entre a agenda do bloco no poder e a do núcleo ideológico. O bloco defende uma pauta ultraliberal sustentada por forças autocráticas, mas não quer abraçar a difusão do irracionalismo nem do antissecularismo, característicos da Escola Sem Partido, conjugados com o fundamentalismo religioso. Essa não é a pauta da escola capitalista no século XXI. 
Em linhas gerais, os dogmas ideológicos da Escola Sem Partido provêm de grupos neopentecostais associados a think tanks de extrema direita, muitos deles patrocinados por congêneres estadunidenses e pelas ideias de Olavo de Carvalho e que lograram grande auditório no período de contendas contra o Partido dos Trabalhadores (FRIGOTTO, 2017; BATISTA; ORSO; LUCENA, 2019).

Contudo, outra contradição tem de ser considerada: as agendas e os projetos do núcleo proveniente das forças armadas não se harmonizam com as pautas do núcleo ideológico. Quer dizer, este último está em contradição simultaneamente com o bloco e com os setores militares.

O exame do aparato de Estado para a grande área de ciência e tecnologia comprova a influência direta da tecnocracia militar e, em menor escala, de quadros provenientes da comunidade acadêmica em postos importantes, entretanto não estão explícitas as conexóes com os setores econômicos (bloco). Cabe enfatizar que muitos quadros do Ministério da Ciência, Tecnologia, Inovaçóes e Comunicaçóes (MCTI) (e do MEC) são provenientes do Instituto Tecnológico da Aeronáutica (ITA) e também da Aman. O ministro Marcos Pontes é tenente-coronel da Força Aérea Brasileira, engenheiro formado pelo ITA. A direçáo superior da área foi confiada a quadros relacionados com o aparato militar. O Conselho Nacional de Desenvolvimento Científico e Tecnológico (CNPq) é chefiado pelo engenheiro João Luiz Filgueiras de Azevedo, pesquisador do Instituto de Aeronáutica e Espaço e professor do ITA, com doutorado na Universidade Stanford; a Financiadora de Estudos e Projetos, pelo general Waldemar Barroso Magno Neto, engenheiro com graduação e mestrado no Instituto Militar de Engenharia, instituição em que ocupou o cargo de reitor (2014-2017), e atuou também como instrutor na Aman.

O ministro Ricardo Vélez Rodriguez provém da Universidade Federal de Juiz de Fora (UFJF), da área de ciências da religião, e foi colaborador da Escola de Comando e Estado-Maior do Exército (Eceme). Em seu gabinete, estão o advogado Tiago Tondinelli (chefe de gabinete), o coronel Robson Santos da Silva, assessor especial, especialista em educação a distância, ex-diretor da Associação Brasileira de Ensino a Distância, modalidade de ensino que tem sido defendida pelo presidente, e o coronel da reserva do exército Ayrton Pereira Rippel, chefe de gabinete adjunto.

No que se refere às áreas do MEC que possuem interface direta com o setor de ciência e tecnologia, a Coordenação de Aperfeiçoamento de Pessoal de Nível Superior ficou a cargo do então reitor do ITA, o engenheiro Anderson Ribeiro Correia, oficial da reserva não remunerada da marinha. O secretário executivo Luiz Antônio Tozi é proveniente do Centro Paula Souza e pós-graduado pelo ITA. O coronel-aviador Ricardo Wagner Roquetti foi nomeado diretor de programa da Secretaria Executiva do MEC, foi pró-reitor do ITA e estudou na 
Universidade da Força Aérea. O oficial da reserva não remunerada da marinha Eduardo Miranda Freire de Melo é secretário executivo adjunto.

A Secretaria de Educação Superior (Sesu) ficou a cargo do professor da Universidade de Brasília Mauro Rabelo. A Empresa Brasileira de Serviços Hospitalares foi confiada ao general Oswaldo de Jesus Ferreira, engenheiro formado na Aman, que atuou na coordenação dos temas da infraestrutura durante a campanha e que chegou a ser cogitado como ministro da Infraestrutura.

O Instituto Nacional de Estudos e Pesquisas Educacionais Anísio Teixeira (Inep) é chefiado pelo engenheiro Marcus Vinícius Rodrigues, proveniente da Fundação Getulio Vargas (FGV), graduado pela Universidade Federal do Ceará e doutor em Engenharia de Produção pela Universidade Federal do Rio de Janeiro. O seu chefe de gabinete é o general Francisco Mamede de Brito Filho, que atuou como chefe do Estado-Maior do Comando Militar do Nordeste, foi chefe do Gabinete de Segurança Institucional em 2008 e 2009, comandou um batalhão brasileiro na missão de paz da ONU no Haiti e a Força de Pacificação do Complexo da Maré, no Rio de Janeiro.

O coronel da reserva remunerada dos bombeiros Luiz Tadeu Vilela Blumm foi nomeado diretor de gestão de fundos e benefícios do Fundo Nacional de Desenvolvimento da Educação, coordenador do Fies e do Fundo de Manutenção e Desenvolvimento da Educação Básica. Foi da equipe de transição do governo.

A equipe que mantém conexão direta com o núcleo ideológico atua principalmente na educação básica e profissional. É formada pelo próprio ministro da Educaçáo e por colaboradores como Murilo Resende Ferreira, doutor em Economia pela FGV, proveniente do Escola Sem Partido, nomeado inicialmente para a Diretoria de Avaliação da Educação Básica do Inep (nomeação posteriormente revogada) e depois como assessor da Sesu (VENAGLIA, 2019), e Carlos Nadalim, da Secretaria de Alfabetização (formado em Direito pela Universidade Estadual de Londrina, mestre em Educação). O secretário de Educaçấo Profissional e Tecnológica Alexsandro Ferreira de Souza, como o ministro, é da área de ciências da religião (UFJF) e docente da rede de educação básica do Espírito Santo. A Secretaria de Modalidades Especiais de Educação ficou a cargo de Bernardo Goytacazes de Araújo, graduado em Filosofia pela UFJF (PERES; SEMIS, 2019). A Secretaria de Regulação e Supervisão da Educação Superior, sob responsabilidade de Marco Antônio Barroso Faria, provém da Universidade do Estado de Minas Gerais, possui mestrado e doutorado em Ciências da Religião pela UFJF e é ex-aluno de Vélez. A Secretaria de Educação Básica foi confiada, por indicaçáo de Tozi, a Tania Leme de Almeida, professora do Centro Paula Souza, da Faculdade de Tecnologia do Estado de Sáo Paulo (Fatec) de São Carlos, formada em Engenharia Agronômica pela Universidade Estadual Paulista Júlio de Mesquita Filho e doutora em Engenharia Civil-Hidráulica pela Universidade de São Paulo (USP). 
A conexão do ministro da Educação com a esfera militar é indireta, por meio da Eceme. Em livro, destaca o pensamento de Antonio Paim sobre o papel da Escola Superior de Guerra na "racionalização do Estado" e "na 'formulação de objetivos nacionais permanentes', que constituem imperativos morais que pairam acima das discussóes políticas" (RODRÍGUEZ, 2015, p. 267). O quadro intelectual de referência, para Rodríguez, é o general Golbery do Couto e Silva:

\begin{abstract}
Alicerçado na proposta de "autoritarismo instrumental" elaborada por Oliveira Vianna. [...] Essa seria a essência da tarefa de construção ou engenharia política, que estaria garantida pela racionalidade que assiste ao Poder Executivo, como diretor de todo processo. [...] A democracia [...] somente poderia vir pelo amargo caminho do Estado autoritário e centralizador. [...] Tal é a lição de Golbery (RODRÍGUEZ, 2015, p. 267-268).
\end{abstract}

Foi anunciado forte estímulo ao modelo das escolas militares, sustentado pela criação da Subsecretaria de Fomento às Escolas Cívico-Militares.

A real agenda do MEC ainda não foi definida e possivelmente será resultante de interaçóes entre os referidos núcleos. Existe a perspectiva de deslocar recursos da educação superior para a educação básica - "As universidades devem ficar reservadas para uma elite intelectual, que não é a mesma elite econômica" (PASSARELLI, 2019). A agenda MEC preconiza maior autonomia dos estados e municípios, havendo possibilidade de criação do voucher educação, proposição com forte aderência na Escola de Chicago e afim, por conseguinte, ao bloco no poder. $\mathrm{O}$ ministro propugna maior apoio ao ensino fundamental e à formaçáo profissional, além de estancar a expansão de recursos para a educação superior. Admite a possibilidade de cobrança de mensalidade dos estudantes das universidades: "Gosto do regime vigente na Colômbia. Lá, paga-se de acordo com a renda" (apud CASTRO; VIEIRA, 2019). Defende que os reitores devem estar submetidos à lei de responsabilidade fiscal específica: "O [Cadastro de Pessoa Física] CPF deles deve ser rastreado pelo juiz Sérgio Moro, por que não?" (apud CASTRO; VIEIRA, 2019). No que se refere à educação básica, as metas para os primeiros 100 dias incluíram o Programa Ciência na Escola (elaborado sob influência do MCTI) e, sem uma definição sistemática, a agenda de promoção da ética e da cidadania e o programa nacional de definição de soluções didáticas e pedagógicas para a alfabetização. Em sentido extraescolar, propóe regulamentar, por meio de medida provisória, a educaçáo domiciliar (REDAÇÃO, 2019), medida afim à agenda do núcleo ideológico representado pelo Ministério da Mulher, da Família e dos Direitos Humanos.

É possível constatar, em síntese, a existência de um conjunto de dirigentes militares, muitos da Aman, provenientes do ITA e do Centro Paula Souza. 
A considerar a formação e a trajetória de suas instituiçóes de origem, desenvolverão uma agenda educacional predominantemente instrumental (o que não quer dizer isenta de ideologia), especialmente na educação superior. O grupo do círculo acadêmico-político do ministro, proveniente da filosofia, possivelmente estará mais propenso a trabalhar a agenda moral e o conceito de cidadania defendido pelas suas referências intelectuais, sobretudo na educação básica e profissional. Inexistem indicaçôes precisas sobre como se darão, e se vão acontecer, as conexóes dos agrupamentos presentes no MEC com a agenda educacional do bloco no poder, principalmente do TPE. Temas como o uso de vouchers no financiamento das escolas podem ser um dos pontos de convergência, mas, como assinalado, dificilmente como consenso de todos os setores que efetivamente participam do TPE. Nos processos escolares, a convergência não está estabelecida. Essa não é uma questão secundária.

\section{Em prol da educação pública, laica, gratuita e capaz de assegurar formação científica, cultural, histórico-social, tecnológica e artística}

Até o momento, não foi analisado como os movimentos educacionais associados ao mundo do trabalho estáo se movendo na conjuntura. Esse é o fulcro da análise das condiçóes para mudanças na correlação de forças. Retomando Poulantzas (1981), tais sujeitos não compóem e estão em contradiçáo com o bloco no poder. De fato, o período que compreende de 1995 a 2015 pode ser caracterizado como de tensóes dos sindicatos e entidades acadêmicas com a perspectiva educacional do bloco no poder. Inicialmente operacionalizada pelo Programa para Reforma Educativa na América Latina e Caribe e pelo Movimento Brasil Competitivo, o protagonismo dominante na educação assumiu maior dimensão em 2007, com a criação do TPE. Os reformadores empresariais (FREITAS, 2014) passaram a ter enorme influência na definição das políticas, como o Plano de Desenvolvimento da Educação (2007) e, mais tarde, o Plano Nacional de Educação (PNE - Lei no 13.005/14).

$\mathrm{Na}$ análise da participação dos trabalhadores e entidades acadêmicas comprometidos com a educação pública, é preciso diferenciar três períodos:

- 1995 a 2004, decênio em que as lutas pela educação pública eram organizadas por uma frente de unidade de ação entre sindicatos, entidades acadêmicas e, difusamente, partidos, no Fórum Nacional em Defesa da Escola Pública (FNDEP), centrado nas lutas pela LDB e pelo PNE. Nesse período foram realizados os Congressos Nacionais de Educação;

- 2005 a 2015, em virtude da implosáo do FNDEP (2005), o decênio caracterizou-se pela fragmentaçẫo das lutas, em conflito com a agenda 
do bloco no poder, destacando a chamada meritocracia, avaliaçáo de competências, uso de índices, implementaçáo do piso salarial nacional e, embora sem unidade de ação, de contendas tanto em favor do segundo PNE como, por parte de outros sindicatos e movimentos, contra as aberturas ao setor privado-mercantil e as pautas do TPE contidas nos projetos de lei que deram origem à Lei no 13.005/14;

- 2016 a 2018, período de fragmentaçáo de lutas, em geral econômico-corporativas, e no qual sobressaiu a agenda da Escola Sem Partido e de movimentos correlatos, gerando conflitos pontuais de grande intensidade, criminalização de docentes, movimentos de difamação de professores.

Nos dois últimos períodos, ocorreram numerosas greves, porém, embora com pautas semelhantes, realizadas em âmbitos locais, sem força nacional. Paulatinamente, outra agenda, até então residual, foi ganhando auditório. Com a ofensiva final contra o governo Dilma Rousseff e culminando nas eleiçóes de 2018, esta agenda assumiu lugar proeminente e mesmo central. Focada na suposta doutrinação política (depois nomeada como marxismo cultural) e nos temas relativos às questóes de gênero, ela colonizou grande parte das ofensivas da extrema direita nas redes sociais. Projetos de lei sobre o tema foram apresentados na Câmara dos Deputados e nas assembleias legislativas, chegando a vetar o uso da palavra gênero nas escolas, tipificando o suposto assédio ideológico como crime, provocando até mesmo o Supremo Tribunal Federal a se manifestar contrário a tais projetos nos estados. A narrativa compreende questóes como o chamado kit gay, a rigor uma cartilha nunca distribuída, elaborada para combater as discriminaçóes e a homofobia, a afirmaçấo de que a defesa do aborto objetiva impedir a chegada do messias, asseveraçóes impulsionadas pelo partido evangélico.

Como assinalado, os conflitos decorrentes da pauta do Escola Sem Partido chegaram às escolas e, por isso, interpelaram os sindicatos, que passaram a ter de direcionar açōes contra os seus preceitos. Ao mesmo tempo, em virtude da crise em diversos estados, os sindicatos tiveram de enfrentar a falta de pagamento de salários e outros temas econômico-corporativos. O paradoxo é que, nesse último período, o confronto com a agenda do bloco no poder perdeu centralidade, indicando um momento da correlação de forças em que existem aproximaçóes entre a agenda dos sindicatos e das entidades acadêmicas com a agenda do bloco no poder (sobretudo nos temas da liberdade de cátedra e de expressão e de questôes de gênero).

A despeito do projeto de lei que dispóe sobre a Escola Sem Partido ter sido retirada da pauta, seus preceitos seguem circulando e provocando consequências negativas, comprometendo a laicidade das escolas (vide feriados religiosos, 
escolarização doméstica, retomada do ensino de moral e cívica). Ademais, pautas e práticas como a imposição de métodos de alfabetização, a possibilidade de uso de vouchers, alteraçóes nos editais de compra de livros didáticos, permitindo publicidade e simplificando o rigor científico, o descumprimento da prática consuetudinária de nomeação dos reitores escolhidos por suas comunidades, entre outros exigem frentes em defesa da educação pública muito mais amplas e capilarizadas nos setores democráticos da sociedade.

A defesa da escola pública, laica, gratuita, comprometida com o conhecimento científico, a liberdade de cátedra, o fortalecimento das políticas de cotas, o compromisso com um real universalismo em que caibam todos os rostos, as práticas antirracistas e contra as discriminaçóes estarão na ordem do dia, sob risco de pesadas derrotas civilizatórias. Já foi destacada a existência de nichos no governo que, embora periféricos em relação ao bloco no poder, poderão avançar em suas pautas em virtude das conexóes entre as suas bancadas e o bloco no poder, que não hesitará em fazer alianças para viabilizar as chamadas reformas.

É preciso considerar, simultaneamente, a pauta específica da educação, em que determinados temas aglutinarão forças sociais que podem estar em conflito com outras pautas e, também, as expectativas do bloco no poder, as posiçóes das classes-apoio e a dos movimentos e iniciativas em defesa da educaçáo pública, laica, gratuita e de qualidade. É um quadro sumamente complexo, em que as alianças serão fragilizadas pelas contradiçóes entre a economia, a política e a educação.

O fortalecimento dos setores que defendem agenda distinta da do núcleo ideológico passa pela hegemonia das perspectivas laica e secular, que requerem a valorização da função formativa, científica, que possibilite que cada criança e jovem possa fazer uso crítico e autônomo da própria razão, conforme apregoou Kant (1784), em Resposta à pergunta: Que é o Iluminismo?

A defesa da laicidade e da formação de um espírito científico pode aproximar os defensores da educação pública, os grupos empresariais representados pelo TPE, os dirigentes da Confederação Nacional da Indústria e militares em geral, embora com perspectivas diversas e até mesmo conflituosas. Em certas condiçóes, pode ser possível unidade de ação interclassista. De outra parte, a possibilidade de vouchers na educação básica contará com o apoio das entidades empresariais que compóem o bloco no poder e também das igrejas, desejosas de se apropriarem do fundo público, mas isso gerará conflitos com parte do TPE, com entidades científicas e sindicais da área e com os movimentos em defesa da educação pública.

Objetivamente, não é possível controlar as variáveis sobre como atuarão os sujeitos coletivos do bloco no poder, visto o fato de que a agenda da classe pode envolver alianças muito estreitas com as classes-apoio fundamentalistas. O posicionamento dos quadros provenientes das forças armadas igualmente é incerto. 
Por tradição e formação, tenderiam a estar no movimento em prol da educação pública, laica e científica, contudo podem se aproximar do núcleo ideológico na esfera doutrinária. A única variável que os defensores da educação pública podem controlar é a construção da unidade de ação, uma vontade política necessária para alterar a correlaçáo de forças. Isso está no âmbito das iniciativas dos diversos sindicatos, coletivos, partidos, movimentos sociais e setores da sociedade civil comprometidos com essa causa.

\section{Notas}

1. Brasil (2017) afirma: "Garantia dos poderes constitucionais, da Lei e da ordem”, por "decisão do Presidente da República, de forma episódica, em área previamente estabelecida e por tempo limitado, com o propósito de assegurar o pleno funcionamento do estado democrático de direito, da paz social e da ordem pública”.

2. Ver também: DIAP, 2019.

\section{Referências}

BATISTA, E. L.; ORSO, P. J.; LUCENA, C. (orgs.). Escola sem Partido ou escola da mordaça e do partido único a serviço do capital. Uberlândia: Navegando Publicaçóes, 2019.

BRASIL. Ministério da Defesa. Exército Brasileiro. Estado-Maior do Exército. Sistema de Planejamento do Exército (Siplex). Fase IV. Concepção Estratégica do Exército. Brasil: Ministério da Defesa, 2017. Disponível em: <https://pt.scribd.com/document/367392132/ Concepcao-Estrategica-do-Exercito-Brasileiro-2017\#fullscreen\&from embed $>$. Acesso em: 3 de fevereiro de 2019.

CASTRO, G.; VIEIRA, M. C. Entrevista Ricardo Vélez Rodríguez, Faxina ideológica. Veja, $1^{\circ}$ fev. 2019.

DEPARTAMENTO INTERSINDICAL DE ASSESSORIA PARLAMENTAR (DIAP). Eleiçóes 2018: bancada evangélica cresce na Câmara e no Senado. Diap, 17 out. 2018. Disponível em: <http://www.diap.org.br/index.php/noticias/noticias/28532-eleicoes-2018bancada-evangelica-cresce-na-camara-e-no-senado $>$. Acesso em: 16 de janeiro de 2019.

DEPARTAMENTO INTERSINDICAL DE ASSESSORIA PARLAMENTAR (DIAP). Novo Congresso Nacional em números. 2019-2023. Diap, 2019. Disponível em: $<$ http://www.diap.org.br/index.php/publicacoes/finish/100-novo-congresso-nacionalem-numeros-2019-2023/3912-novo-congresso-nacional-em-numeros-2019-2023>. Acesso em: 5 de fevereiro de 2019.

FATTORELLI, M. L.; ÁVILA, R. Orçamento 2019 revela que o rombo está no gasto com a dívida pública. Monitor Mercantil, 17 jan. 2019. Disponível em: <https:// monitordigital.com.br/or-amento-2019-revela-que-o-rombo-est-no-gasto-com-a-d-vidap-blica-2>. Acesso em: 3 de fevereiro de 2019. 
FERNANDES, F. A ditadura militar e os papéis políticos dos intelectuais na América Latina. In: FERNANDES, F. Circuito fechado. São Paulo: Hucitec, 1976.

FREITAS, L. C. de. Os reformadores empresariais da educação e a disputa pelo controle do processo pedagógico na escola. Educaçáo \& Sociedade, Campinas, v. 35, n. 129, p. 1085-1114, dez. 2014. Disponível em: <http://www.scielo.br/scielo.php?script=sci arttext\&pid=S0101-73302014000401085\&lng=en\&nrm=iso >. Acesso em: 2 fev. 2019. http://dx.doi.org/10.1590/ES0101-73302014143817

FRIGOTTO, G. (org.) Escola "sem” partido. Esfinge que ameaça a educação e a sociedade brasileira. Rio de Janeiro: UERJ, LPP, 2017.

GRAMSCI, A. Cadernos do cárcere. 5. ed. Rio de Janeiro: Civilização Brasileira, 2012. v. 3.

KANT, I. Resposta à pergunta: Que é o iluminismo? 1784. Tradução de Artur Morão. Disponível em: <http://www.lusosofia.net/textos/kant o iluminismo 1784.pdf $>$. Acesso em: 26 de janeiro de 2019.

LAVAL, C. L' École n'est pas une entreprise. Paris: Éditions la Découverte, 2003.

LEHER, R. Universidade e heteronomia cultural: um estudo a partir de Florestan Fernandes. Rio de Janeiro: Consequência, 2018.

MENDES, C. H. Direito penal express. Época, n. 1.075, p. 82, 11 fev. 2019.

MURAKAWA, F. Colombiano comandará a educação. Valor, 23 nov. 2018. Disponível em: <https://www.valor.com.br/politica/5995661/colombiano-comandara-educacao $>$. Acesso em: 16 de janeiro de 2019.

MURAKAWA, F.; DELGADO, M. Bancada evangélica veta o nome de Mozart Ramos para educação. Valor, 21 nov. 2018. Disponível em: <https://www.valor.com.br/ politica/5993169/bancada-evangelica-veta-o-nome-de-mozart-ramos-para-educacao $>$. Acesso em: 15 de janeiro de 2019.

NEVES, R. Governo Bolsonaro já passa de 30 militares em postos-chave. Congresso em Foco, 18 jan. 2019. Disponível em: < https://congressoemfoco.uol.com.br/governo/governobolsonaro-ja-passa-de-30-militares-em-postos-chavel>. Acesso em: 3 de fevereiro de 2019.

PASSARELLI, H. Ideia de universidade para todos não existe, diz ministro da Educação. Valor, 28 jan. 2019. Disponível em: <https://www.valor.com.br/brasil/6088217/ideia-de-universidadepara-todos-nao-existe-diz-ministro-da-educacao $>$. Acesso em: 2 de fevereiro de 2019.

PERES, P.; SEMIS, L. Quem é quem no MEC de Jair Bolsonaro. Nova Escola, 3 jan. 2019. Disponível em: <https://novaescola.org.br/conteudo/14880/quem-e-quem-nomec-de-jair-bolsonaro $>$. Acesso em: 15 de janeiro de 2019.

POULANTZAS, N. O Estado, o poder e nós. In: BALIBAR, E. et al. O Estado em Discussáo. Lisboa: Ediçôes 70, 1981.

REDAÇÃO. Novo governo promete mudanças profundas na educação. Senado Notícias, 28 jan. 2019. Disponível em: <https://www12.senado.leg.br/noticias/ materias/2019/01/28/governo-promete-mudancas-profundas-na-educacao $>$. Acesso em: 2 de fevereiro de 2019. 
RODRÍGUEZ, R. V. O republicanismo brasileiro. Londrina: Centro de Pesquisas Estratégicas Paulino Soares de Souza da UFJF, 2015.

UOL. Para Moro, críticas indicam que decreto de posse de armas foi "ponderado", UOL Notícias, 16 jan. 2019. Disponível em: <https://noticias.uol.com.br/politica/ultimasnoticias/2019/01/16/para-moro-criticas-indicam-que-decreto-de-posse-de-arma-foiponderado.htm >. Acesso em: 25 de janeiro de 2019.

VENAGLIA, Guilherme. Diretor responsável pelo Enem é demitido um dia após nomeação. Veja, 18 jan. 2019. Disponível em: <https://veja.abril.com.br/politica/ diretor-responsavel-pelo-enem-e-demitido-um-dia-apos-nomeacao/>. Acesso em: 25 de janeiro de 2019.

\section{SOBRE O AUTOR}

Roberto Leher é professor titular do Programa de Pós-Graduação em Educação do Departamento de Administração Educacional da Faculdade de Educação da Universidade Federal do Rio de Janeiro (UFRJ).

Recebido em 12 de fevereiro de 2019.

Aceito em 29 de julho de 2019. 